\title{
Práticas interprofissionais no combate à obesidade infantil
}

\author{
Acadêmicos: André Ruiz de Oliveira, Arielle Anzai, Tatiana Lulai, Luca Canadá \\ Orientadores: Cláudia Moreira Brito, Maria Edna de Melo, Marcio Correa Macini
}

\begin{abstract}
A obesidade infantil já é uma epidemia crescente em nosso país, com uma etiologia complexa e multifatorial, decorrente fatores ambientais e genéticos. Para o tratamento da criança obesa, é importante a atuação de equipe multiprofissional e práticas colaborativas, que produzem resultados ainda melhores quando associadas à cooperação da família em todo o processo terapêutico.
\end{abstract}

A Liga tem como objetivo capacitar o acadêmico a realizar técnicas adequadas de avaliação, diagnóstico e tratamento da obesidade e síndrome metabólica na infância e na adolescência. Essa capacitação é realizada através das práticas de anamnese, exame físico e interpretação de exames complementares nos pacientes, com foco especial nas doenças associadas à obesidade e desenvolvimento. As discussões fornecem bases teóricas da fisiopatologia e do tratamento, com abordagens não medicamentosa, farmacológica e cirúrgica da obesidade em crianças e adolescentes.

A Liga é composta por uma grade heterogênea de funcionários, profissionais e estagiários. Entre os profissionais de saúde, conta-se com endocrinologistas, nutricionistas, psicólogas, psiquiatra, pediatra e acadêmicos de nutrição e medicina.

Os atendimentos acontecem uma vez por semana e o acompanhamento dos pacientes ocorre mensalmente nos primeiros 6 meses. Após esse período, os atendimentos são realizados de acordo com a necessidade de cada um. As condutas são individualizadas e dependem principalmente da participação do paciente e evolução do tratamento.

Em todas as visitas os pacientes são atendidos pela psicologia, em grupo e, quando necessário, individualmente. Ainda em grupos, eles participam de aulas e atividades de educação nutricional e hábitos de vida. Na sequencia ocorrem os atendimentos individuais pelas equipes de medicina e nutrição. Em alguns casos, existe o atendimento em conjunto de nutrição e medicina, aumentando a prática interprofissional e a integralidade do atendimento. Logo após os atendimentos, cada caso é discutido entre os diferentes profissionais de saúde presentes e os alunos de nutrição e medicina. Periodicamente acontecem reuniões de discussão de todos os casos para avaliação interna de medidas a serem tomadas e reestruturação das abordagens.

A liga atende crianças e adolescentes com diagnóstico de obesidade (índice de massa corporal > p97 na curva da Organização Mundial de Saúde). Inicialmente, os pacientes passam por um processo de triagem e então são subdivididos em grupos de acordo com faixa etária, gravidade da doença e presença de alterações metabólicas.

Com essas atividades, a liga proporciona uma experiência rara durante a graduação para a prática colaborativa interprofissional. Essa relação entre profissionais de diferentes áreas promove maior envolvimento dos pacientes e da familia no tratamento, o que é fundamental para a obtenção de bons resultados no seguimento doenças crônicas em crianças e adolescentes. Essa abordagem interprofissional e mais integral do paciente tem um papel significativo na redução de muitos desafios enfrentados dentro da liga e projeta-se ainda para a prática profissional futura dos acadêmicos, não apenas com foco na obesidade infantil, mas também em diversas outras áreas da medicina. 